\title{
Prevention of Alcohol-Heightened Aggression by CRF-R I Antagonists in Mice: Critical Role for DRN-PFC Serotonin Pathway
}

\author{
Isabel M Quadros',3, Lara S Hwa', Akiko Shimamoto', Julia Carlson', Joseph F DeBold' and \\ Klaus A Miczek*,1,2 \\ 'Department of Psychology, Tufts University, Medford, MA, USA; 'Departments of Neuroscience, Psychiatry, and Pharmacology, \\ Tufts University, Boston, MA, USA
}

\begin{abstract}
Alcohol can escalate aggressive behavior in a significant subgroup of rodents, humans, and nonhuman primates. The present study investigated whether blockade of corticotropin-releasing factor receptor type I (CRF-RI) could prevent the emergence of alcoholheightened aggression in mice. The serotonin (5-HT) pathway from the dorsal raphe nucleus (DRN) to the medial prefrontal cortex (mPFC) by CRF-RI was investigated as a possible target for the prevention of alcohol-heightened aggressive behavior. Male CFW mice that reliably exhibited aggressive behaviors after consuming I g/kg of alcohol received systemic or intra-DRN administration of CRF-R I antagonists, CP-154,526 or MTIP, before a confrontation with a male conspecific. Blockade of DRN CRF-RI receptors with both antagonists significantly reduced only alcohol-heightened aggression, whereas systemic administration reduced both alcohol-heightened and species-typical aggression. Next, a 5-HTI A agonist, 8-OH-DPAT, was coadministered with CP-I54,526 into the DRN to temporarily disrupt 5-HT activity. This manipulation abolished the antiaggressive effects of intra-DRN CP-154,526. In the mPFC, in vivo microdialysis revealed that extracellular 5-HT levels were increased in mice that consumed alcohol and were then injected with CP- I54,526, both systemically or intra-DRN. Neither alcohol nor CP-I54,526 alone affected 5-HT release in the mPFC. The present results suggest the DRN as a critical site for CRF-RI to modulate alcohol-heightened aggression via action on the serotonergic DRN-PFC pathway.

Neuropsychopharmacology (2014) 39, 2874-2883; doi:I0.1038/npp.2014.139; published online 9 July 20I4
\end{abstract}

\section{INTRODUCTION}

Intense outbursts of aggressive behavior have been linked to alcohol drinking in humans and other animal species (see, eg, Bushman and Cooper, 1990; Krug et al, 2002; Roizen, 1997). Evidence for alcohol as a promoter of escalated levels of aggressive behavior has been established in laboratory settings, particularly in susceptible subgroups of individuals (Cloninger, 1987; Miczek et al, 2004). In mice, low to moderate doses of alcohol can escalate aggressive behaviors to levels that are significantly higher and more injurious than species-typical aggression (Miczek et al, 1998; Miczek and de Almeida, 2001), modeling critical features of alcoholescalated aggression.

Understanding the neurobiological mechanisms underlying escalated aggression, particularly those mediating alcohol-heightened aggression, has been a challenge. Con-

*Correspondence: Dr KA Miczek, Department of Psychology, Tufts University, 530 Boston Avenue, Medford, MA 02155, USA, Tel: + 617627 3414, Fax: + 6176273939 ,

E-mail: Klaus.Miczek@tufts.edu

${ }^{3}$ Current address: Department of Psychobiology, Universidade Federal de Sao Paulo, Sao Paulo, Brazil

Received 7 March 20।4; revised 3 June 20।4; accepted 5 June 20।4; accepted article preview online I| June 2014 siderable evidence supports the involvement of serotonergic mechanisms in aggression; however, it remains controversial whether it is an increase or decrease of serotonin (5-HT) activity that promotes escalated aggression (Takahashi et al, 2011; de Boer and Koolhaas, 2005). Ascending serotonergic projections arise mainly from the dorsal raphe nucleus (DRN) to innervate forebrain and limbic regions (Jacobs and Azmitia, 1992; Molliver, 1987). Of particular interest, 5 -HT levels in the medial prefrontal cortex (mPFC) are dynamically regulated in preparation for, during, and in recovery from an aggressive confrontation in rats (van Erp and Miczek, 2000). Phasic changes in 5-HT activity may also affect alcohol-heightened aggression and other forms of escalated aggression, as evidenced by infusion of drugs targeting 5-HT1 receptors into the DRN and subregions of the PFC (Bannai et al, 2007; de Almeida et al, 2006; Faccidomo et al, 2008).

DRN 5-HT neurons are finely tuned by different inputs, one of which is corticotropin-releasing factor (CRF; Valentino and Commons, 2005). CRF has two receptor subtypes, CRF-R1 and CRF-R2, both found in high densities in the DRN (Chalmers et al, 1995; Swanson et al, 1983). Infusion of CRF or drugs targeting CRF receptors in the DRN significantly affects the firing rate of 5-HT neurons in a dose-dependent manner (Kirby et al, 2000; Lowry et al, 
2000), and also controls 5-HT release in the PFC, striatum, and other limbic regions (Forster et al, 2008; Lukkes et al, 2008; Price and Lucki, 2001).

In the present study, we targeted CRF-R1 within the DRN and the 5-HT projections to the mPFC as a putative mechanism for the emergence of alcohol-heightened aggression. CRF mechanisms significantly modulate maternal and intermale aggression in mice, hamsters, and rats (Elkabir et al, 1990; Farrokhi et al, 2004; Gammie et al, 2004; Gammie and Stevenson, 2006; Tazi et al, 1987). Although evidence points to a key role of CRF-R1 in several features of alcoholrelated behaviors and effects (Heilig and Koob, 2007), its involvement in alcohol-heightened aggression needs to be examined.

\section{MATERIALS AND METHODS}

\section{Housing}

Male CFW Swiss-derived mice (Charles River Laboratories, Wilmington, MA), $\sim 6$ weeks old at arrival, were housed in pairs with a female conspecific in standard polycarbonate cages $(28 \times 17 \times 14 \mathrm{~cm})$ for 3 weeks before any manipulation. Additional CFW male mice were housed in groups of $8-11$ per cage $(48 \times 26 \times 14 \mathrm{~cm})$ and used as intruders described below. Animals were maintained in a temperature- and humidity-controlled room $\left(21 \pm 1{ }^{\circ} \mathrm{C}\right.$ and $35-40 \%$, respectively), with lights on from $1900 \mathrm{~h}$ to $0700 \mathrm{~h}$. Food was available ad libitum, and access to water was limited to $4 \mathrm{~h} /$ day to enhance alcohol self-administration, as described below (Faccidomo et al, 2008). Experimental procedures were approved by the Institutional Animal Care and Use Committee of Tufts University, and followed the Guide for the Care and Use of Laboratory Animals (National Research Council of The National Academies, 2010).

\section{Drugs}

Two nonpeptidergic, high-affinity, and selective CRF-R1 antagonists were used in these experiments. CP-154,526 was the first nonpeptidergic CRF-R1 antagonist described to effectively cross the blood-brain barrier (Schulz et al, 1996), with well-characterized pharmacological and behavioral effects in the literature (see Seymour et al, 2003). Our previous studies (Hwa et al, 2013) revealed that it was suitable for intra-DRN infusions as well as for systemic administration (intraperitoneal (i.p.)), enabling appropriate drug effect comparisons (systemic vs intracranial). MTIP is a more recently developed molecule, showing high affinity and specificity to CRF-R1 with no relevant affinity to any of 74 other receptor and channels tested, good oral bioavailability, important behavioral effects (similar to those of other CRF-R1 antagonists), and high promise for entering clinical trials at the time these experiments were carried out (Gehlert et al, 2007).

CP-154,526 (butyl-ethyl-[2,5-dimethyl-7-(2,4,6-trimethylphenyl)-7H-pyrrolo[2,3-d]pyrimidin-4-yl]-amine) was either donated (Pfizer, New York, NY) or commercially purchased (Tocris Bioscience, Bristol, UK). MTIP (3-(4-chloro-2morpholin-4-yl-thiazol-5-yl)-8-(1-ethylpropyl)-2,6-dimethylimidazo[1,2-b]pyridazine) was kindly donated by Dr Markus Heilig (NIAAA/NIH). 8-OH-DPAT (( \pm )-8-hydroxy-2-(di- $n$ propylamino)tetralin) hydrobromide) was purchased from
Sigma-Aldrich. For i.p. administration, CP-154,526 was dissolved in $0.1 \%$ carboxymethyl cellulose (CMC), and MTIP was dissolved in $2 \%$ Tween-80. For intracerebral administrations, CP-154,526, MTIP, and 8-OH-DPAT were dissolved in artificial CSF (aCSF).

\section{Alcohol Self-Administration}

Experimental males were trained for alcohol self-administration using an operant conditioning panel inserted into their home cage (Miczek and de Almeida, 2001). The panel had two troughs with one connected to a syringe located behind the panel and filled with $6 \%$ alcohol or water. The infrared beam inside the troughs detected nose pokes, with every fifth nose poke (fixed ratio 5 (FR5)) delivering a $50-\mu \mathrm{l}$ droplet of either $6 \%$ alcohol solution $(\mathrm{w} / \mathrm{v})$ or water, as controlled by computer software (Med Associates, St Albans, VT). Self-administration was terminated when animals achieved the moderate dose of $1 \mathrm{~g} / \mathrm{kg}$ of alcohol or equivalent volume of water (corresponding to 8-12 reinforcements, depending on body weight). Alcohol self-administration sessions were limited to twice a week to avoid extensive exposure to alcohol. Within 2-3 weeks of training, all mice completed alcohol or water reinforcement sessions within $4 \mathrm{~min}$.

\section{Assessment of Aggression}

Concomitant with self-administration training, experimental males established aggressive behavior against a naive group-housed intruder male (Miczek and O'Donnell, 1978). Briefly, each experimental male confronted an intruder in the experimental male's home cage, for $5 \mathrm{~min}$ after the first attack bite. The female was removed from the experimental male's home cage during confrontations. Frequency of attack bites was recorded to assess aggression levels. The criterion used for stable aggression levels was defined as the frequency of attack bites across 3 consecutive sessions varied within $15 \%$ for each experimental male (criterion met within 7-12 confrontations). Approximately $5 \%$ of mice were excluded from the study because of a failure in establishing stable and reliable aggressive behaviors.

\section{Alcohol-Heightened Aggression}

After experimental males displayed stable levels of drinking and fighting, they were tested for aggression $15 \mathrm{~min}$ following $1 \mathrm{~g} / \mathrm{kg}$ alcohol drinking (Miczek and de Almeida, 2001). For comparison purposes, baseline aggression levels were determined after consuming water. Confrontations were recorded and analyzed by a trained observer using The Observer software (Observer XT 8.0, Noldus Information Technology, Wageningen, The Netherlands). Frequency and duration of aggressive behaviors, such as attack bites and sideways threats, as well as nonaggressive composite behaviors, such as walking, rearing, and grooming, were determined (Miczek and O'Donnell, 1978). Aggressive confrontations were conducted in $48-72 \mathrm{~h}$ intervals, for a total of 6-8 aggression tests, alternating between water and alcohol tests. After completing these tests, experimental mice were subjected to the following drug experiments. 


\section{Systemic Injections of CRF-R1 Antagonists}

In two separate sets of mice, the effects of CRF-R1 receptor antagonists, CP-154,526 or MTIP, were assessed in aggressive mice after consuming water or $1 \mathrm{~g} / \mathrm{kg}$ alcohol. On a test day, experimental mice completed self-administration of alcohol or water, and were immediately injected i.p. with CP-154,526 (vehicle, 10,17 , or $30 \mathrm{mg} / \mathrm{kg}, n=18$ ), or MTIP $(3,10$, or $30 \mathrm{mg} / \mathrm{kg}, n=13)$. At $15 \mathrm{~min}$ after drug treatment, mice confronted a male intruder, as described above. A within-group design was used, in which each mouse was examined under all treatment conditions, in a counterbalanced treatment order. Vehicle tests (2-3 tests) were interspersed between drug tests to ensure the absence of any carryover effects.

\section{Intra-DRN Microinjection of CRF-R1 Antagonists and 8-OH-DPAT}

Separate subsets of experimental mice underwent intracerebral cannulation surgery for the intra-DRN microinjection studies (Takahashi et al, 2010a; Hwa et al, 2013). The mice were anesthetized with a mixture of ketamine $(100 \mathrm{mg} / \mathrm{kg})$ and xylazine $(10 \mathrm{mg} / \mathrm{kg})$, placed in a stereotaxic frame (David Kopf Instruments, Tujunga, CA), and implanted with 26-gauge guide cannulae (PlasticsOne, Roanoke, VA) aimed $2 \mathrm{~mm}$ above the DRN, AP: -4.2 ; ML: \pm 1.5 ; DV: $-1.9 \mathrm{~mm}$ relative to bregma, angled $26^{\circ}$ to the vertical (Paxinos and Franklin, 2001). A 33-gauge obdurator (PlasticsOne) was inserted into the guide cannula to prevent blockage or scarring, and was moved daily to habituate the mice to the handling procedure. After 5 days of recovery, experimental mice were reassessed for alcohol self-administration and aggression at least twice before microinjection experiments.

The procedures used in the study were based on previous work (Faccidomo et al, 2008; Takahashi et al, 2010a). On testing days, immediately after completing the drinking requirement, the obdurator was removed and replaced with a 33-gauge microinjector (PlasticsOne) attached via polyethylene tubing (Intramedic PE-50) to a CMA/100 microinjection pump (CMA Microdialysis AB, Holliston, MA). The microinjector extended $2 \mathrm{~mm}$ beyond the tip of the guide cannula, through which vehicle (aCSF), CP-154,526 (0.3 or $0.6 \mu \mathrm{g})$, or MTIP $(0.345 \mu \mathrm{g}$, matched molarity of $0.3 \mu \mathrm{g}$ CP-154,526 solution) were infused into the DRN $(0.25 \mu \mathrm{l}$ over $2 \mathrm{~min}$ ). Each drug (CP-154,526 or MTIP) was tested in separate cohorts of mice. Doses for microinjection were chosen based on a pilot study detecting promising effects after a $0.3 \mu \mathrm{g}$ infusion of CP-154,526 into the DRN, and parallel studies also showed relevant effects of microinjecting 0.3 and $0.6 \mu \mathrm{g}$ CP-154,526 on alcohol consumption, as recently published by Hwa et al (2013). The microinjector was left in place for an additional $1 \mathrm{~min}$ to allow the drug to diffuse. During the infusion, mice were left unrestrained. After $10 \mathrm{~min}$, a male intruder was introduced into the experimental male's home cage, and a confrontation took place. Each experimental subject received a total of 6-8 microinjections, in counterbalanced order.

In a separate group of mice, $0.3 \mu \mathrm{g}$ 8-OH-DPAT was coadministered with CP-154,526. We used an autoreceptor agonist, 8-OH-DPAT, as a pharmacological tool to transi- ently inhibit 5-HT impulse flow from the DRN (Sprouse and Aghajanian, 1987; Will et al, 2004) during testing for aggressive behavior. As intra-DRN infusion of 8-OH-DPAT has been reported to reduce aggressive and motor behaviors in mice in higher doses ( $1 \mu \mathrm{g}$; Faccidomo et al, 2008), we selected a lower dose, $0.3 \mu \mathrm{g}$, so that baseline aggression and motor activity would be preserved, as shown by Takahashi et al (2010b). After drinking water or $1.0 \mathrm{~g} / \mathrm{kg}$ of alcohol, mice received intra-DRN microinfusions of $0.3 \mu \mathrm{g} \mathrm{CP}-$ 154,526 alone, $0.3 \mu \mathrm{g}$ 8-OH-DPAT alone, a combination of CP-154,526 and 8-OH-DPAT, or vehicle in counterbalanced order and subsequently tests for aggressive behavior commenced.

\section{5-HT Concentrations in the mPFC}

A separate cohort of mice that were trained for alcohol selfadministration and for aggressive behaviors were implanted with a microdialysis CMA/7 guide cannula for 5-HT measurements in the $\mathrm{mPFC}$ (CMA Microdialysis AB) $1 \mathrm{~mm}$ above the mPFC, AP: +2.6 ; ML: -0.3 ; DV: $-0.8 \mathrm{~mm}$ to bregma. For the intra-DRN microinfusion experiment, animals were also implanted with an additional 26-gauge microinjection guide cannula aimed $2 \mathrm{~mm}$ above the DRN, as described above. Mice were allowed to recover from surgery for 1 week, during which they were handled daily. After alcohol self-administration was reestablished, a CMA/7 probe with a $1-\mathrm{mm}$ active membrane was inserted into the mPFC under isoflurane inhalation anesthesia, and the probe was perfused overnight with aCSF at a flow rate of $0.5 \mu \mathrm{l} / \mathrm{min}$. On the following morning, the flow rate was increased to $1.5 \mu \mathrm{l} / \mathrm{min}$, and 20 -min microdialysate samples were collected after $1 \mathrm{~h}$ stabilization. Mice were housed in their home cages during sample collection with no access to water or food to prevent further fluctuations in 5-HT release. Seven baseline samples were collected, and then the operant conditioning panel was inserted into the home cage to allow mice to self-administer $1 \mathrm{~g} / \mathrm{kg}$ of alcohol. Following the completion of alcohol or water self-administration, the mice received an i.p. injection of $17 \mathrm{mg} / \mathrm{kg} \mathrm{CP}-154,526$ or vehicle (systemic study), or a microinjection of $0.3 \mu \mathrm{g}$ CP-154,526 or aCSF into the DRN $(0.25 \mu \mathrm{l}$ over $2 \mathrm{~min}$; intra-DRN study). The 5-HT concentrations were determined with an HPLC system equipped with electrochemical detection (Shimamoto et al, 2011). Changes in 5-HT concentrations are expressed as percent change from average baseline samples for each individual. Injection and probe placements for DRN and $\mathrm{MPFC}$ were verified microscopically after cresyl violet staining (Figure 1).

\section{Statistics}

The effects of alcohol and CRF-R1 antagonists on composite aggressive and nonaggressive behaviors were compared using within-group comparisons, as all experimental subjects were tested under all treatment conditions. Behaviors were analyzed by ANOVAs with repeated measures, with Drinking (alcohol or water) and Treatment (vehicle and drug doses) as main factors. Frequencies of behaviors were used to compare attack bites and sideways threats, whereas nonaggressive behaviors (walking, rearing, grooming) are shown as a composite score, and compared for their 


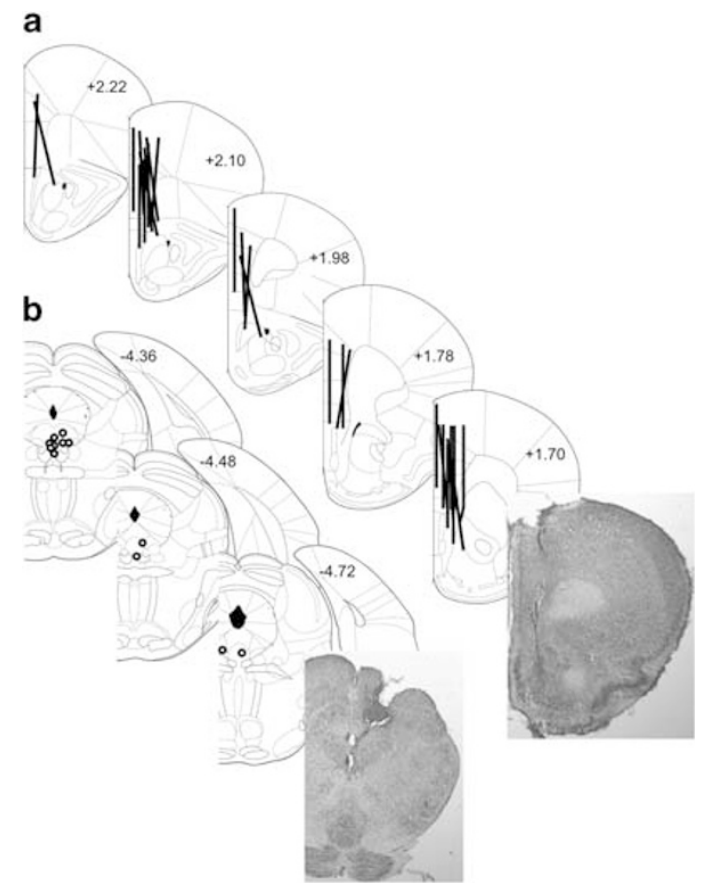

Figure I Representative photomicrographs and coronal sections from a stereotaxic atlas (Paxinos and Franklin, 200I) showing correct mPFC probe placements (lines (a)) and DRN cannula placements for dialysis mice (circles (b))

duration. When appropriate, post hoc Bonferroni tests were conducted to determine the treatment conditions that differed significantly from vehicle and water conditions. For the in vivo microdialysis experiments, one or two-way ANOVAs with repeated measures were carried out for four data points, including one single baseline value computed as the average of three baseline points, and three subsequent data points following drug treatments. For all comparisons, $p<0.05$ was considered significant.

\section{RESULTS}

Systemic Injections of CRF-R1 Antagonists Reduce Both Alcohol-Heightened and Species-Typical Aggression

Alcohol self-administration significantly increased aggressive behaviors, as compared with vehicle trials after mice self-administered water (Figure $2 \mathrm{a}$ and b). There was a significant Drinking effect on the numbers of attack bites $\left(\mathrm{F}_{(1,46)}=7.910, p=0.012\right)$ and sideways threats $\left(\mathrm{F}_{(1,46)}\right.$ $=7.776, p=0.012)$. Systemic injection of CP-154,526 immediately after alcohol or water self-administration significantly decreased aggressive behaviors compared with vehicle conditions in a dose-dependent manner. There was a significant Treatment effect on the number of attack bites $\left(\mathrm{F}_{(3,46)}=26.376, p<0.001\right)$ and sideways threats $\left(\mathrm{F}_{(3,46)}=26.973, p<0.001\right)$. A significant reduction in these two aggressive behaviors was detected in mice self-administering alcohol or water when CP-154,526 was administered in doses of 17 or $30 \mathrm{mg} / \mathrm{kg}(p<0.05)$. CP-154,526 also significantly reduced duration of motor activity $\left(F_{(3,46)}=3.329, p=0.026\right.$, Figure $\left.2 c\right)$, but only at the highest dose $(30 \mathrm{mg} / \mathrm{kg})$, and after water drinking.
Detailed analysis of nonaggressive behaviors are shown in Supplementary Material (Supplementary Table S1).

MTIP administration in mice before a confrontation significantly reduced aggressive behaviors compared with the vehicle administration (Figure $2 \mathrm{~d}$ and e), as indicated by a significant Drug effect on the number of attack bites $\left(\mathrm{F}_{(3,35)}=9.977, p<0.001\right)$ and sideways threats $\left(\mathrm{F}_{(3,35)}=\right.$ 9.221, $p<0.001)$. Bonferroni methods showed a significant reduction in these two aggressive behaviors in mice self-administering alcohol when MTIP was administered in a dose of $30 \mathrm{mg} / \mathrm{kg}(p<0.05)$. In mice self-administering water, MTIP at both 10 and $30 \mathrm{mg} / \mathrm{kg}$ significantly reduced aggressive behaviors $(p<0.05)$. MTIP did not alter motor activity $\left(\mathrm{F}_{(3,35)}=0.781, p=0.512\right)$. Detailed analysis of nonaggressive behaviors are shown in Supplementary Material (Supplementary Table S1).

\section{Blockade of CRF-R1 in DRN Selectively Prevents Alcohol-Heightened Aggression}

Microinfusion of CP-154,526 into the DRN $(n=11)$ significantly suppressed alcohol-heightened aggression, but had no significant behavioral effects when mice consumed water (Figure 3a; Drinking $\times$ Treatment interaction in attack bite frequency: $\left.\mathrm{F}_{(2,20)}=6.02, p=0.009\right)$. Both doses of the antagonist, 0.3 and $0.6 \mu \mathrm{g}$, reduced the frequency of attack bites when aggressive mice had consumed alcohol before the confrontation $(p=0.025$ and $p=0.0003$, respectively). Similar antiaggressive effects were observed for sideways threats (Treatment effect: $\left.\mathrm{F}_{(2,20)}=10.3567, p=0.0008\right)$, particularly when mice were tested after alcohol drinking, as shown in Figure $3 \mathrm{~b}$. Importantly, nonaggressive behaviors were not affected by intra-DRN infusion of CP-154,526 in any of the conditions or doses tested (Figure 3c; see Supplementary Table S2 for detailed results on nonaggressive behaviors). These data suggest a selective antiaggressive effect of the CRF-R1 antagonist on alcohol-related aggression. Intra-DRN MTIP $(n=13)$ had effects on aggressive behaviors similar to those of CP-154,526, such that $0.345 \mu$ g of MTIP into the DRN reduced the number of attack bites when mice consumed alcohol before the confrontations (Drinking $\times$ Treatment interaction: $\mathrm{F}_{(1,12)}=4.74, p=0.0501$, Figure 3d), with no effects of MTIP when mice were tested during water trials. Similar to CP-154,526, intra-DRN infusion of MTIP did not affect nonaggressive behaviors in any of the conditions tested (Figure 3f; see detailed analysis of nonaggressive behaviors in Supplementary Table S2).

In order to control for possible experience factors that might affect the ability of CRF-R1 antagonism to produce antiaggressive effects (ie, repeated alcohol exposure or chronic water restriction), we next tested the effects of intra-DRN infusion of CP-154,526 in mice with no history of alcohol consumption $(n=6)$. Aggressive mice were tested in confrontations with a male intruder after the infusion of increasing doses of $\mathrm{CP}-154,526(0.1,0.3$, and $0.6 \mu \mathrm{g})$ and interspersed vehicle (aCSF) trials. There were no significant effects of CP-154,526 on aggressive or nonaggressive behaviors in mice with no history of alcohol consumption (Table 1). Therefore, the antiaggressive effects of intra-DRN infusion of CRF1 antagonists were selective for conditions 

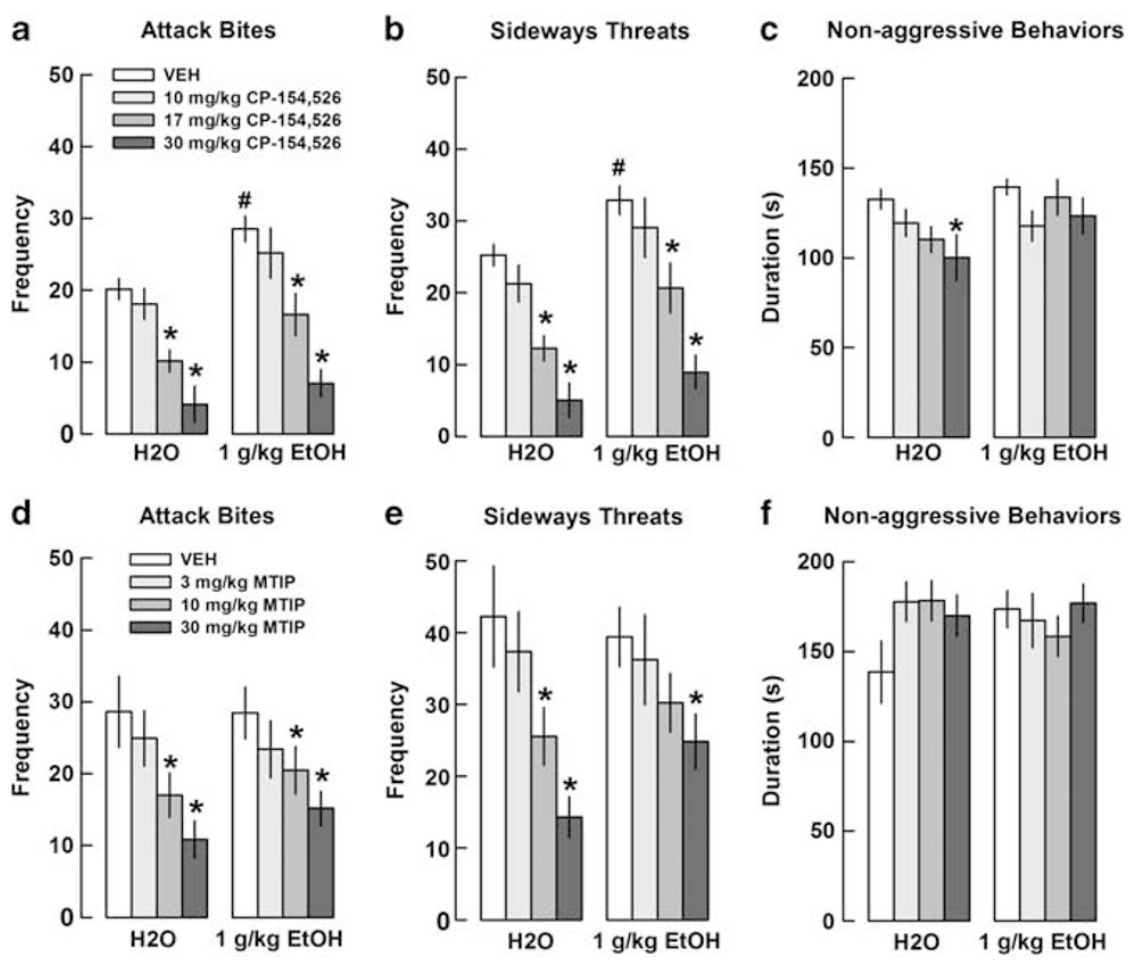

Figure 2 Systemic CRF-RI antagonists reduced aggressive behaviors after alcohol and water consumption. Effect of i.p. injections of CP- I54,526 ( $n=\mid 8$, top three panels) or MTIP ( $n=13$, bottom three panels) on attack bite frequency $(a, d)$, sideways threats (b, e), and nonaggressive locomotor behavior duration (in s; c, f) after oral self-administration of I g/kg ethanol or water. Values are means $\pm \mathrm{SEM} ;{ }^{\#} p<0.05$ compared with water condition, * $p<0.05$ compared with vehicle test (VEH).

of escalated aggression under the influence of a moderate dose of alcohol.

For this series of intra-DRN experiments, eight mice were excluded because of cannula misplacement (four with cannula tips reaching the aqueduct, two in the median raphe, and two were too lateral). Animals with misplaced cannula failed to present effects of the CRF-R1 antagonist treatment, although statistical analysis was not possible because they were distributed across different drug treatment conditions.

\section{Intact 5-HT Activity in the DRN Is Required for the Antiaggressive Effects of CP-154,526}

We next tested whether transient inhibition of 5-HT impulse flow, with the coinfusion of a 5-HT1A agonist, $0.3 \mu \mathrm{g} 8-\mathrm{OH}-\mathrm{DPAT}$, would affect the antiaggressive effects of intra-DRN CP-154,526 on alcohol-related aggression. Intra-DRN infusion of the CRF-R1 antagonist alone was effective in reducing attack bites under the influence of alcohol ( $p=0.012$ vs vehicle), replicating the preceding experiment (significant Drinking and Treatment interaction: $\mathrm{F}_{(3,27)}=7.432, p=0.001$; Figure $\left.4 \mathrm{a}\right)$. The coinfusion of $0.3 \mu \mathrm{g} 8$-OH-DPAT into the DRN prevented the emergence of the antiaggressive effects of $0.3 \mu \mathrm{g}$ CP-154,526 on alcoholheightened aggression ( $p=0.001$ relative to the alcohol-CP154,526 alone condition). However, 8-OH-DPAT alone also reduced alcohol-heightened aggression. When the $0.6 \mu \mathrm{g}$ dose of CP-154,526 was used, $0.3 \mu \mathrm{g} 8$-OH-DPAT could not overcome the antiaggressive effect of CP-154,526 on alcohol-heightened aggression (Figure 4b). Neither drug alone nor in combination significantly altered aggressive behavior in the absence of alcohol. Nonaggressive behaviors were not affected by any of the treatments (data not shown).

\section{5-HT Release Is Enhanced in the mPFC as a Result of CP-154,526 Action under Alcohol Conditions}

Aggression-experienced, alcohol-drinking mice were implanted with the microdialysis guide cannula aimed at the mPFC. During the test, baseline microdialysis samples were collected, and then mice self-administered $1 \mathrm{~g} / \mathrm{kg}$ alcohol. Immediately after alcohol self-administration, mice received either vehicle (CMC) or the intermediate dose of CP-154,526 $(17 \mathrm{mg} / \mathrm{kg})$, i.p., and microdialysis samples continued to be collected for $60 \mathrm{~min}$. There was an overall Group effect on systemic administration of CP-154,526 $\left(\mathrm{F}_{(1,16)}=7.568\right.$, $p=0.032$; Figure 5a). The post hoc tests showed that the group receiving CP-154,526 after drinking alcohol had higher 5-HT levels only during the first $20 \mathrm{~min}$ after treatments when compared with mice receiving vehicle after alcohol consumption. One mouse was excluded because of misplacement of the dialysis probe. The 5-HT levels were not affected by the treatment in this animal.

Following the same experimental design described above, $0.3 \mu \mathrm{g}$ CP-154,526 was infused into the DRN right after completion of the alcohol drinking task. The CRF-R1 antagonist significantly increased prefrontal 5-HT levels after alcohol self-administration compared with baseline $(p<0.05)$. In addition, 5-HT levels were significantly higher 

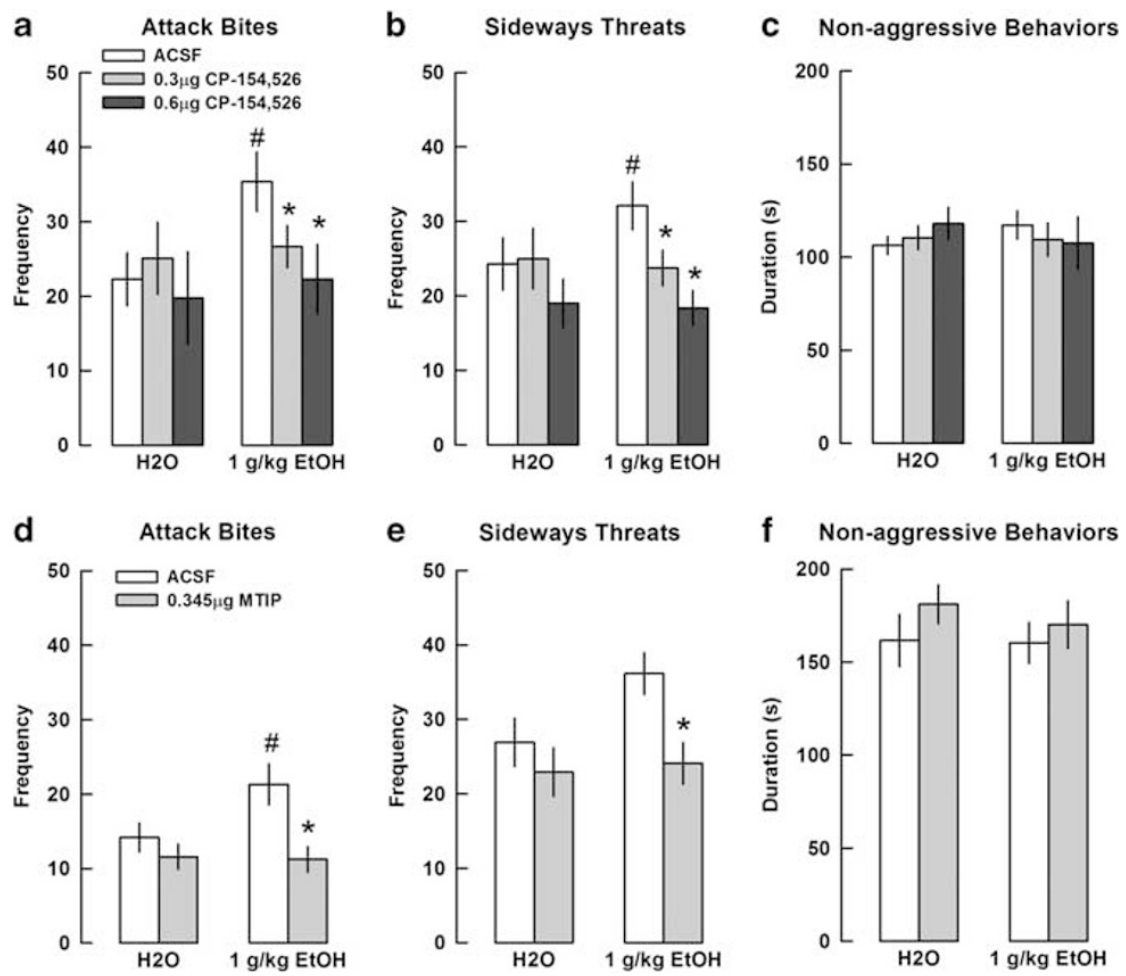

Figure 3 Intra-DRN CRF-RI antagonists selectively reduced alcohol-heightened aggression. Effect of intra-DRN microinjections of CP- I54,526 ( $n=1$ I, top panels) or MTIP ( $n=13$, bottom panels) on frequency of attack bites (a, d) sideways threats (b, e), and nonaggressive locomotor behavior duration (in s; c, f) after oral self-administration of I g/kg ethanol or water. Values are means \pm SEM; ${ }^{*} p<0.05$ compared with water, ${ }^{*} p<0.05$ compared with vehicle.

Table I Behavioral Effects of Intra-DRN Infusion of CP-154,526 in Alcohol-Naive Mice $(n=6)$

\begin{tabular}{|c|c|c|c|c|}
\hline & \multirow[b]{2}{*}{ aCSF (vehicle) } & \multicolumn{3}{|c|}{ CP-I54,526 (in $\mu g$ ) } \\
\hline & & 0.1 & 0.3 & 0.6 \\
\hline \multicolumn{5}{|c|}{ Aggressive behaviors (frequency) } \\
\hline Bites & $26.3(4.04)$ & $20.7(1.7 \mid)$ & $26.2(5.62)$ & $22.0(4.14)$ \\
\hline Threats & $36.8(5.36)$ & $34.8(3.52)$ & $34.3(6.92)$ & $32.8(7.57)$ \\
\hline \multicolumn{5}{|c|}{ Nonaggressive behaviors (duration in s) } \\
\hline Walking & $147.8(21.72)$ & | $48.3(\mid 1.42)$ & | $19.0(24.6 \mid)$ & | $39.0(\mid 4.58)$ \\
\hline Rearing & $24.3(4.59)$ & $28.2(6.85)$ & $29.5(10.89)$ & $26.0(7.65)$ \\
\hline Grooming & $10.5(3.34)$ & $17.7(3.24)$ & I7.5 (4.8I) & $20.7(5.67)$ \\
\hline
\end{tabular}

Data shown as averages $( \pm$ SEM).

in the mice that received CP-154,526 $(n=7)$ compared with the mice that received vehicle treatment $(n=5, p<0.05$; Figure $5 \mathrm{~b}$ ). In total, four animals were excluded. The 5-HT levels were not affected by the manipulation in these animals.

In separate control experiments, we found that $5-\mathrm{HT}$ levels were unaltered in mice that only self-administered $1 \mathrm{~g} / \mathrm{kg}$ alcohol $\left(\mathrm{F}_{(5,26)}=0.378, p=0.859, n=7\right.$, data not shown) or in mice receiving CP-154,526 alone $(17 \mathrm{mg} / \mathrm{kg}$, i.p.), without the combined influence of alcohol $\left(\mathrm{F}_{(6,11)}\right.$ $=1.103, p=0.419, n=4$, data not shown). One animal presented misplaced probe and was not included in the data analysis.

\section{DISCUSSION}

The current set of studies reveals a key role for CRF-R1 in aggression that is escalated by alcohol in male mice via modulation of 5-HT activity in the DRN-mPFC pathway. We found that systemic administration of CRF-R1 antagonists CP-154,526 and MTIP prevented alcohol-heightened aggression and species-typical aggression, whereas infusion of CRF-R1 antagonists into the DRN selectively prevented alcohol-heightened aggression. By transiently inhibiting DRN impulse flow with a low dose of 8-OH-DPAT, we found that intact DRN 5-HT activity is required for a CRF$\mathrm{R} 1$ antagonist to prevent escalated alcohol aggression in a dose-dependent manner. Furthermore, in vivo microdialysis studies suggest that increases in 5-HT release in the mPFC are associated with the antiaggressive effects resulting from blockade of CRF-R1 after alcohol drinking.

\section{Blockade of CRF-R1: Systemic vs DRN Effects on Alcohol-Related Aggression}

Selective antiaggressive effects on escalated aggression promoted by alcohol were only observed when CRF-R1 antagonists were locally infused into the DRN, whereas more generalized antiaggressive effects were observed with systemic blockade of CRF-R1. These results suggest that CRF-R1 in areas other than the DRN probably modulate species-typical levels of aggressive behavior, whereas DRN CRF-R1 are particularly important when aggression is performed under the influence of alcohol. In all but one of the several experiments of this study (MTIP systemic 


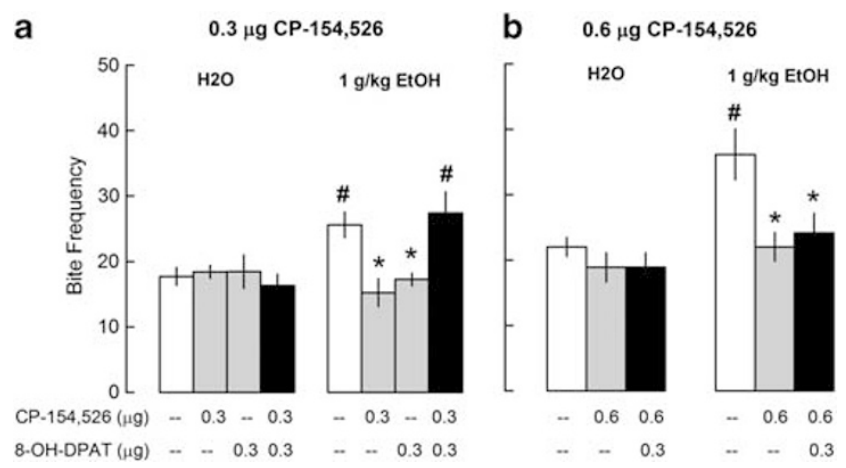

Figure 4 Intact DRN 5-HT function is required for CRF-RI reduction of alcohol-heightened aggression. Effect of intra-DRN microinjections of $0.3 \mu \mathrm{g}$ (a) or $0.6 \mu \mathrm{g}$ (b) CP-I54,526 and $0.3 \mu \mathrm{g}$ 8-OH-DPAT, 5-HTIA agonist, separately and in combination, on attack bite frequency after oral self-administration of $\mathrm{I} g / \mathrm{kg}$ ethanol or water. Values are means $\pm \mathrm{SEM}$; $n=10 ;{ }^{*} p<0.05$ compared with water. ${ }^{*} p<0.05$ compared with vehicle.

experiment), alcohol-heightened aggression was significantly observed in the overall group of animals, despite the known individual differences in this phenomenon (see Miczek et al, 2004). Such differences may have contributed to the absence of alcohol-escalated aggression in that particular cohort of mice. However, the antiaggressive effects of the CRF-R1 antagonists were observed in that and all other experiments involving alcohol in this study.

Importantly, CRF-R1 antagonists in the DRN did not affect other nonaggressive motor behaviors. In nonalcoholdrinking mice, intra-DRN blockade of CRF-R1 failed to affect baseline levels of aggressive behavior, supporting the hypothesis that DRN CRF-R1 may be critical only in conditions of escalated aggression (Miczek et al, 2013). It remains to be determined whether CRF-R1 blockade in the DRN is also effective in reducing other types of escalated aggression.

Evidence for antiaggressive effects because of antagonism of CRF-R1 have been obtained with another selective, nonpeptidergic CRF-R1 antagonist, SSR125543A, in male Syrian hamsters (Farrokhi et al, 2004), as well as with a nonselective antagonist, $\alpha$-helical CRF, in stress-induced defensive aggression in rats (Tazi et al, 1987). However, CRF-R1 knockout mice exhibited normal levels of intermale aggression compared with wild types (Gammie and Stevenson, 2006). Furthermore, the involvement of CRF-R1 in other types of aggression, such as maternal aggression, seems to be secondary as compared with the role of CRF-R2 (see, eg, D'Anna et al, 2005; Gammie et al, 2005; Gammie and Stevenson, 2006). The present data show an involvement of CRF-R1 in the modulation of alcohol-heightened aggression in male mice, and point to the DRN as a critical site for these selective antiaggressive effects.

An important role for CRF and its associated peptides, Urocortins 1,2, and 3, has been proposed in the modulation of several different social behaviors (Hostetler and Ryabinin, 2013). There is evidence that the direct administration of CRF itself may facilitate or induce pro-aggressive and defensive effects after i.c.v. or intra-amygdala infusions in male rats (Elkabir et al, 1990; Tazi et al, 1987), as well as in rainbow trout (Carpenter et al, 2009). However, there is also evidence that the effects of CRF are dose, condition, and

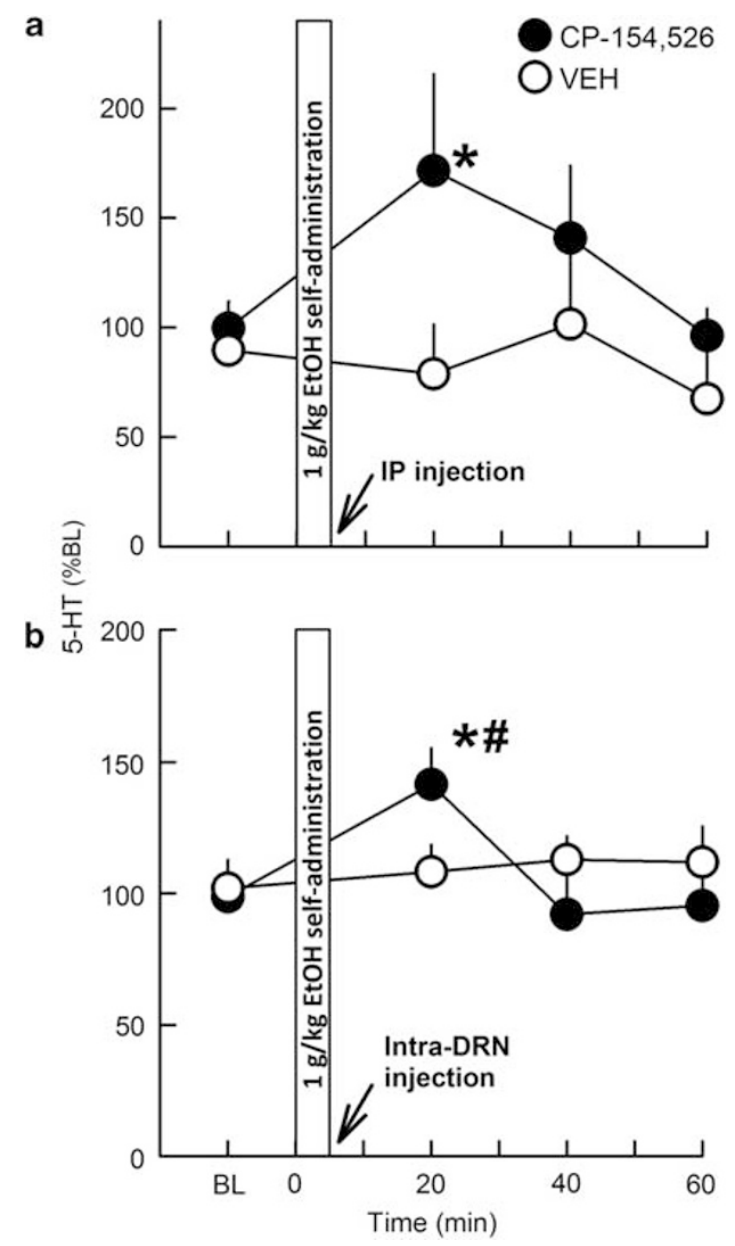

Figure 5 Systemic and intra-DRN CRF-RI antagonist increased mPFC 5HT. Effect of i.p. injection $(n=4$, a) or intra-DRN microinjection $(n=7, b)$ of CP-154-526 (filled symbols) or vehicle (open symbols) on 5-HT levels in mPFC after oral self-administration of I g/kg ethanol. Shown are 5-HT levels (pg) expressed as percent (\%) change from baseline over time ( $\mathrm{min}$ ). Values are means \pm SEM; ${ }^{*} p<0.05$ compared with water, ${ }^{*} p<0.05$ compared with vehicle.

species dependent (Elkabir et al, 1990; Tazi et al, 1987; Mele et al, 1987). For example, in isolated male mice, i.c.v. infusion of CRF or sauvagine, a CRF-R2 agonist, significantly reduced aggressive behaviors (Mele et alet al, 1987). Both CRF and Urocortins also have suppressive effects on maternal aggression, mostly dependent on CRF-R2 (D'Anna et al, 2005; Gammie et al, 2004, 2005).

Although this is the first study on the modulation of alcohol-heightened aggression by CRF-R1 signaling, the involvement of CRF systems in alcohol drinking and alcohol dependence has been extensively explored in animal models (Heilig and Koob, 2007). After repeated and chronic exposure to alcohol, rats show hyperactive extrahypothalamic CRF activity, as indicated by increases in CRF levels and its receptors in the extended amygdala (Merlo Pich et al, 1995; Olive et al, 2002; Sommer et al, 2008). Systemic or intra-amygdaloid blockade of CRF-R1 attenuates increased alcohol seeking and intake in alcohol-dependent animals (Funk et al, 2006; Gehlert et al, 2007; Sommer et al, 2008; Heilig and Koob, 2007) or in high-alcohol-consuming mice (Sparta et al, 2008). We also recently observed that CP154,526 microinjected in the DRN reduced alcohol drinking 
in rats and mice that drank excessively, but not in those animals that showed low-level or moderate alcohol drinking (Hwa et al, 2013). Sensitized anxiety-like behavior and increased drinking, in the context of withdrawal from alcohol, can also be prevented by CRF-R1 antagonists in the DRN and other sites (Huang et al, 2010; Knapp et al, 2011). Together, these results and ours indicate that CRF appears to play a role in excessive alcohol-related behaviors, whether it is escalated drinking leading to dependence, or escalated aggression caused by an acute, moderate dose of ethanol.

\section{CRF-5-HT Interactions in the DRN: a Role in Alcohol-Escalated Aggression}

We targeted CRF receptors in the DRN for reducing alcohol-heightened aggression because of the long-standing hypothesis that serotonin activity is critical for the development and expression of pathological aggression (Takahashi et al, 2011; Takahashi and Miczek, 2013). Serotonergic pathways, including uptake and storage processes, and somatodendritic and terminal pre- and postsynaptic receptor mechanisms have been investigated for the neural control of aggressive behavior (de Boer and Koolhaas, 2005; Takahashi and Miczek, 2013). Tonic levels of 5-HT are critical determinants in the genesis of impulsive outbursts, while its impulse flow in the DRN can reduce several types of species-specific and maladaptive aggressive behaviors. Phasic changes in 5-HT emerge during aggressive episodes as illustrated by a sudden decrease in PFC 5-HT during a confrontation (Van Erp and Miczek, 2000).

In order to assess the involvement of DRN 5-HT neurons in mediating the effects of CRF-R1 antagonists, we used 8-OH-DPAT as a tool to transiently inhibit DRN 5-HT impulse flow during aggressive behavior. A low dose of 8-OH-DPAT was used so that baseline levels of aggression would be preserved (Takahashi et al, 2010b), as higher doses result in behavioral inhibition (Faccidomo et al, 2008). As expected, intra-DRN infusion of CP-154,526 abolished alcohol-heightened aggression. In the presence of 8-OH-DPAT, however, the CRF-R1 antagonist failed to prevent alcohol-escalated aggression. These results suggest the requirement of intact 5-HT activity in the DRN for the antiaggressive effects of CP-154,526 to emerge under the influence of alcohol drinking. Intriguingly, the infusion of 8-OH-DPAT alone in the DRN also prevented alcoholheightened aggression in the absence of the CRF-R1 antagonist. Although 8-OH-DPAT could reverse the lower dose of the CRF-R1 antagonist, it could not reverse the higher dose of the CRF-R1 antagonist, suggesting 5-HT may be more crucial at the lower dose of CP-154,526. The relationship between CRF-R1 and 5-HTIA receptors may be complex. The fact that CRF-R1 and 5-HT1A receptors can be found in both 5-HT and GABAergic neurons in the DRN (see, eg, Beck et al, 2004; Kirby et al, 2003) further complicates the understanding of this CRF-5-HT interaction in the DRN, with a putative role for a GABAergic modulation (Takahashi et al, 2010b). Thus, the precise mechanism by which 8-OH-DPAT influences alcohol-heightened aggression, and interacts with CRF-R1 receptors, remains to be determined.

Among the forebrain and limbic structures that are innervated by the $\mathrm{DRN}$, the $\mathrm{mPFC}$ is likely to be a critical target for the modulation of aggressive behavior (Olivier, 2004). This pathway is of particular interest in view of dysfunctions found in the mPFC of violent criminals and aggressive psychiatric patients (see, eg, Best et al, 2002; Raine et al, 1994), as well as in genetically selected highly aggressive rodents (Caramaschi et al, 2008). Moreover, in vivo microdialysis of male aggressive rats shows a reduction in PFC 5-HT levels during an aggressive confrontation with a male conspecific, suggesting a proximal involvement of 5-HT levels in the display of aggressive behaviors (van Erp and Miczek, 2000). Our in vivo microdialysis results suggest that increases in $\mathrm{mPFC} 5-\mathrm{HT}$ levels are associated with the antiaggressive effects of a CRF-R1 antagonist. Indeed, in alcohol-consuming mice, CP154,526 administered systemically or directly into the DRN promoted significant increases in 5-HT concentrations in the mPFC. Serotonin concentrations peaked in the first sample after alcohol consumption and drug treatment (within $20 \mathrm{~min}$ ) in a time frame consistent with the period when antiaggressive effects of CP-154,526 were observed in behavioral studies. Alcohol consumption or CP-154,526 administration alone did not affect mPFC 5-HT levels.

Our findings contrast with those of Takahashi et al (2010b) who reported increased 5-HT levels in the mPFC as a result of the $\mathrm{GABA}_{\mathrm{B}}$ agonist baclofen infusion in the DRN in a dose that increases aggression above species-typical levels of aggressive behavior. In our case, consumption of an aggression-heightening dose of alcohol failed to affect 5-HT levels in the mPFC, whereas increased 5-HT was observed when escalated aggression was prevented by the CRF-R1 antagonist. Furthermore, mice in our microdialysis experiments were experienced with aggression and alcohol drinking, and both of these factors have been shown to affect 5-HT levels and transmission in the mPFC (see, eg, Caramaschi et al, 2008; Faccidomo et al, 2008). Mice used in the microdialysis assays in the study of Takahashi et al (2010b) were neither experienced aggressors nor alcohol consumers. Together, one could speculate that different 5-HT mechanisms may be recruited under different types of aggression (baclofen $v s$ alcohol-heightened aggression), or the prevention thereof. Indeed, a more intricate role for different 5-HT neurons in the modulation of aggression has been proposed (see, eg, de Boer and Koolhaas, 2005; Takahashi et al, 2011). Despite presenting a PFC-5-HT mechanism for the antiaggressive effects of CRF-R1 antagonists under alcohol conditions, the present study does not rule out the participation of other brain regions and pathways associated with the emergence of alcohol-heightened aggression.

Electrophysiological and microdialysis studies have consistently shown that i.c.v. or intra-DRN microinjections of CRF, or drugs targeting CRF receptors, exert potent modulatory control over 5-HT neurons (Kirby et al, 2000; Lowry et al, 2000), modulating 5-HT release in striatum, amygdala, lateral septum, and prefrontal cortex (Amat et al, 2004; Forster et al, 2008; Lukkes et al, 2008; Price et al, 1998; Price and Lucki, 2001). Evidence suggests that activation of DRN CRF-R1 predominantly inhibits whereas CRF-R2 activation predominantly increases 5-HT function and output (Valentino and Commons, 2005; Valentino et al, 2010). Interpreting our data according to this model, one could speculate that when CRF-R1 antagonists are infused in the DRN after alcohol drinking, blockade of CRF-R1 
could cause a shift in CRF actions in favor of CRF-R2 activation. In turn, this shift could contribute to the observed increases in 5-HT concentrations in the $\mathrm{MPFC}$, which is the proposed mechanism for the observed antiaggressive effects of CRF1 antagonists on alcohol-escalated aggression. Ongoing studies are characterizing the involvement of CRF-R2 in the DRN in alcohol-related aggression.

In conclusion, these studies implicate CRF-R1 modulation of the serotonergic DRN-mPFC pathway as a critical mechanism for the antiaggressive effects of CRF-R1 antagonism, particularly in the context of alcohol-heightened aggression in male mice. It would be interesting to determine whether this circuit is also important for other types of escalated aggression such as frustration-heightened aggression or maternal aggression. Understanding the neurobiology of escalated aggression in social animals is a step forward toward pharmacological treatment for intense pathological aggression. This research proposes CRF-R1 antagonists as putative tools for preventing this hazardous behavior, especially under the influence of alcohol. Clinical therapeutic use of CRF-R1 antagonists should be in sight for controlling alcohol-related abuse and aggression, once new and safe bioavailable molecules targeting CRF-R1 are made available.

\section{FUNDING AND DISCLOSURE}

This research was funded by NIAAA (AA013983 to KAM, PI) and IMQ was supported in part by ABMRF/The Foundation for Alcohol Research. We thank Dr Markus Heilig (NIAAA) for providing MTIP. The authors declare no conflict of interest.

\section{ACKNOWLEDGEMENTS}

We acknowledge Mr Tom Sopko for outstanding assistance.

\section{REFERENCES}

Amat J, Tamblyn JP, Paul ED, Bland ST, Amat P, Foster AC et al (2004). Microinjection of urocortin 2 into the dorsal raphe nucleus activates serotonergic neurons and increases extracellular serotonin in the basolateral amygdala. Neuroscience 129: 509-519.

Bannai M, Fish EW, Faccidomo S, Miczek KA (2007). Antiaggressive effects of agonists at 5-HT(1B) receptors in the dorsal raphe nucleus of mice. Psychopharmacology 193: 295-304.

Beck SG, Pan YZ, Akanwa AC, Kirby LG (2004). Median and dorsal raphe neurons are not electrophysiologically identical. J Neurophysiol 91: 994-1005.

Best M, Williams JM, Coccaro EF (2002). Evidence for a dysfunctional prefrontal circuit in patients with an impulsive aggressive disorder. Proc Natl Acad Sci USA 99: 8448-8453.

Bushman BJ, Cooper HM (1990). Effects of alcohol on human aggression: integrative research review. Psychol Bull 107: 341-354.

Caramaschi D, de Boer SF, de Vries H, Koolhaas JM (2008). Development of violence in mice through repeated victory along with changes in prefrontal cortex neurochemistry. Behav Brain Res 189: 263-272.

Carpenter RE, Korzan WJ, Bockholt C, Watt MJ, Forster GL, Renner KJ et al (2009). Corticotropin releasing factor influences aggression and monoamines: modulation of attacks and retreats. Neuroscience 158: 412-425.

Chalmers DT, Lovenberg TW, De Souza EB (1995). Localization of novel corticotropin-releasing factor receptor (CRF2) mRNA expression to specific subcortical nuclei in rat brain: comparison with CRF1 receptor mRNA expression. J Neurosci 15: 6340-6350. Cloninger CR (1987). Neurogenetic adaptive mechanisms in alcoholism. Science 236: 410-416.

D’Anna KL, Stevenson SA, Gammie SC (2005). Urocortin 1 and 3 impair maternal defense behavior in mice. Behav Neurosci 119: 1061-1071.

de Almeida RM, Rosa MM, Santos DM, Saft DM, Benini Q, Miczek KA (2006). 5-HT 1 B receptors, ventral orbitofrontal cortex, and aggressive behavior in mice. Psychopharmacology (Berl) 185: 441-450.

de Boer SF, Koolhaas JM (2005). 5-HT1A and 5-HT1B receptor agonists and aggression: a pharmacological challenge of the serotonin deficiency hypothesis. Eur J Pharmacol 526: 125-139.

Elkabir DR, Wyatt ME, Vellucci SV, Herbert J (1990). The effects of separate or combined infusions of corticotrophin-releasing factor and vasopressin either intraventricularly or into the amygdala on aggressive and investigative behaviour in the rat. Regul Pept 28: 199-214.

Faccidomo S, Bannai M, Miczek KA (2008). Escalated aggression after alcohol drinking in male mice: dorsal raphe and prefrontal cortex serotonin and $5-\mathrm{HT}_{1 \mathrm{~B}}$ receptors. Neuropsychopharmacology 33: 2888-2899.

Farrokhi C, Blanchard DC, Griebel G, Yang M, Gonzales C, Markham C et al (2004). Effects of the CRF1 antagonist SSR125543A on aggressive behaviors in hamsters. Pharmacol Biochem Behav 77: 465-469.

Forster GL, Pringle RB, Mouw NJ, Vuong SM, Watt MJ, Burke AR et al (2008). Corticotropin-releasing factor in the dorsal raphe nucleus increases medial prefrontal cortical serotonin via type 2 receptors and median raphe nucleus activity. Eur J Neurosci 28: 299-310.

Funk CK, O’Dell LE, Crawford EF, Koob GF (2006). Corticotropinreleasing factor within the central nucleus of the amygdala mediates enhanced ethanol self-administration in withdrawn, ethanol-dependent rats. J Neurosci 26: 11324-11332.

Gammie SC, Hasen NS, Stevenson SA, Bale TL, D’Anna KL (2005). Elevated stress sensitivity in corticotropin-releasing factor receptor 2 deficient mice decreases maternal, but not intermale aggression. Behav Brain Res 160: 169-177.

Gammie SC, Negron A, Newman SM, Rhodes JS (2004). Corticotropin-releasing factor inhibits maternal aggression in mice. Behav Neurosci 118: 805-814.

Gammie SC, Stevenson SA (2006). Intermale aggression in corticotropin-releasing factor receptor 1 deficient mice. Behav Brain Res 171: 63-69.

Gehlert DR, Cippitelli A, Thorsell A, Le AD, Hipskind PA, Hamdouchi C et al (2007). 3-(4-Chloro-2-morpholin-4-ylthiazol-5-yl)-8-(1-ethylpropyl)-2,6-dimethyl- imidazo[1,2-b]pyridazine: a novel brain-penetrant, orally available corticotropinreleasing factor receptor 1 antagonist with efficacy in animal models of alcoholism. J Neurosci 27: 2718-2726.

Heilig M, Koob GF (2007). A key role for corticotropin-releasing factor in alcohol dependence. Trends Neurosci 30: 399-406.

Hostetler CM, Ryabinin AE (2013). The CRF system and social behavior: a review. Front Neurosci 7: 92.

Huang MM, Overstreet DH, Knapp DJ, Angel R, Wills TA, Navarro $M$ et al (2010). Corticotropin-releasing factor (CRF) sensitization of ethanol withdrawal-induced anxiety-like behavior is brain site specific and mediated by CRF-1 receptors: relation to stress-induced sensitization. J Pharmacol Exp Ther 332: 298-307.

Hwa LS, DeBold JF, Miczek KA (2013). Alcohol in excess: CRF(1) receptors in the rat and mouse VTA and DRN. Psychopharmacology (Berl) 225: 313-327.

Jacobs BL, Azmitia EC (1992). Structure and function of the brain serotonin system. Physiol Rev 72: 165-229.

Kirby LG, Pernar L, Valentino RJ, Beck SG (2003). Distinguishing characteristics of serotonin and non-serotonincontaining cells in the dorsal raphe nucleus: electrophysio- 
logical and immunohistochemical studies. Neuroscience 116: 669-683.

Kirby LG, Rice KC, Valentino RJ (2000). Effects of corticotropinreleasing factor on neuronal activity in the serotonergic dorsal raphe nucleus. Neuropsychopharmacology 22: 148-162.

Knapp DJ, Overstreet DH, Huang M, Wills TA, Whitman BA, Angel RA et al (2011). Effects of a stressor and corticotrophin releasing factor on ethanol deprivation-induced ethanol intake and anxiety-like behavior in alcohol-preferring $\mathrm{P}$ rats. Psychopharmacology 218: 179-189.

Krug EG, Dahlberg LL, Mercy JA, Zwi AB, Lozito R (eds) (2002). World Report on Violence and Health. World Health Organization: Geneva.

Lowry CA, Rodda JE, Lightman SL, Ingram CD (2000). Corticotropin-releasing factor increases in vitro firing rates of serotonergic neurons in the rat dorsal raphe nucleus: evidence for activation of a topographically organized mesolimbocortical serotonergic system. J Neurosci 20: 7728-7736.

Lukkes JL, Forster GL, Renner KJ, Summers CH (2008). Corticotropin-releasing factor 1 and 2 receptors in the dorsal raphe differentially affect serotonin release in the nucleus accumbens. Eur J Pharmacol 578: 185-193.

Mele A, Cabib S, Oliverio A, Melchiorri P, Puglisi-Allegra S (1987). Effects of corticotropin releasing factor and sauvagine on social behavior of isolated mice. Peptides 8: 935-938.

Merlo Pich E, Lorang M, Yeganeh M, Rodriguez De Fonseca F, Raber J et al (1995). Increase of extracellular corticotropin-releasing factor-like immunoreactivity levels in the amygdala of awake rats during restraint stress and ethanol withdrawal as measured by microdialysis. J Neurosci 15: 5439-5447.

Miczek KA, Barros HM, Sakoda L, Weerts EM (1998). Alcohol and heightened aggression in individual mice. Alcohol Clin Exp Res 22: $1698-1705$.

Miczek KA, de Almeida RMM (2001). Oral drug self-administration in the home cage of mice: alcohol- heightened aggression and inhibition by the 5-HT1B agonist anpirtoline. Psychopharmacology (Berl) 157: 421-429.

Miczek KA, de Boer SF, Haller J (2013). Excessive aggression as model of violence: a critical evaluation of current preclinical methods. Psychopharmacology (Berl) 226: 445-458.

Miczek KA, Fish EW, de Almeida RMM, Faccidomo S, DeBold JF (2004). Role of alcohol consumption in escalation to violence. Ann NY Acad Sci 1036: 278-289.

Miczek KA, O'Donnell JM (1978). Intruder-evoked aggression in isolated and nonisolated mice: effects of psychomotor stimulants and 1-dopa. Psychopharmacology 57: 47-55.

Molliver ME (1987). Serotonergic neuronal systems: what their anatomic organization tells us about function. J Clin Psychopharmacol 7: 3S-23S.

National Research Council of The National Academies (2010). Guide for the Care and Use of Laboratory Animals. 8th edn. The National Academies Press: Wahington, DC.

Olive MF, Koenig HN, Nannini MA, Hodge CW (2002). Elevated extracellular CRF levels in the bed nucleus of the stria terminalis during ethanol withdrawal and reduction by subsequent ethanol intake. Pharmacol Biochem Behav 72: 213-220.

Olivier B (2004). Serotonin and aggression. Ann NY Acad Sci 1036: 382-392.

Paxinos G, Franklin KBJ (2001). The Mouse Brain in Stereotaxic Coordinates, 2nd edn. Academic Press: San Diego.

Price ML, Curtis AL, Kirby LJ, Valentino RJ, Lucki I (1998). Effects of corticotropin-releasing factor on brain serotonergic activity. Neuropsychopharmacology 18: 492-502.
Price ML, Lucki I (2001). Regulation of serotonin release in the lateral septum and striatum by corticotropin-releasing factor. J Neurosci 21: 2833-2841.

Raine A, Buchsbaum MS, Stanley J, Lottenberg S, Abel L, Stoddard J (1994). Selective reductions in prefrontal glucose metabolism in murderers. Biol Psychiatry 36: 365-373.

Roizen J (1997). Epidemiological issues in alcohol-related violence. In: Galanter M (ed). Recent Developments in Alcoholism. Plenum Press: New York, pp 7-41.

Seymour PA, Schmidt AW, Schulz DW (2003). The pharmacology of CP-154,526, a non-peptide antagonist of the CRH1 receptor: a review. CNS Drug Rev 9: 57-96.

Shimamoto A, DeBold JF, Holly EN, Miczek KA (2011). Blunted accumbal dopamine response to cocaine following chronic social stress in female rats: exploring a link between depression and drug abuse. Psychopharmacology (Berl) 218: 271-279.

Schulz DW, Mansbach RS, Sprouse J, Braselton JP, Collins J, Corman M et al (1996). CP-154,526: a potent and selective nonpeptide antagonist of corticotropin releasing factor receptors. Proc Natl Acad Sci USA 93: 10477-10482.

Sommer WH, Rimondini R, Hansson AC, Hipskind PA, Gehlert DR, Barr CS et al (2008). Upregulation of voluntary alcohol intake, behavioral sensitivity to stress, and amygdala crhr1 expression following a history of dependence. Biol Psychiatry 63: 139-145.

Sparta DR, Sparrow AM, Lowery EG, Fee JR, Knapp DJ, Thiele TE (2008). Blockade of the corticotropin releasing factor type 1 receptor attenuates elevated ethanol drinking associated with drinking in the dark procedures. Alcohol Clin Exp Res 32: 259-265.

Sprouse JS, Aghajanian GK (1987). Electrophysiological responses of serotoninergic dorsal raphe neurons to 5-HT1A and 5-HT1B agonists. Synapse 1: 3-9.

Swanson LW, Sawchenko PE, Rivier J, Vale WW (1983). Organization of ovine corticotropin-releasing factor immunoreactive cells and fibers in the rat brain: an immunohistochemical study. Neuroendocrinology 36: 165-186.

Takahashi A, Kwa C, DeBold JF, Miczek KA (2010a). GABA(A) receptors in the dorsal raphé nucleus of mice: escalation of aggression after alcohol consumption. Psychopharmacology 211: 467-477.

Takahashi A, Miczek KA (2013). Neurogenetics of aggressive behavior: studies in rodents. Curr Top Behav Neurosci (e-pub ahead of print 7 December 2013; doi:10.1007/7854_2013_263).

Takahashi A, Quadros IM, de Almeida RM, Miczek KA (2011). Brain serotonin receptors and transporters: initiation $v s$ termination of escalated aggression. Psychopharmacology (Berl) 213: 183-212.

Takahashi A, Shimamoto A, Boyson CO, DeBold JF, Miczek KA (2010b). GABA(B) receptor modulation of serotonin neurons in the dorsal raphe nucleus and escalation of aggression in mice. J Neurosci 30: 11771-11780.

Tazi A, Dantzer R, Le Moal M, Rivier J, Vale W, Koob GF (1987). Corticotropin-releasing factor antagonist blocks stress-induced fighting in rats. Regul Pept 18: 37-42.

Valentino RJ, Commons KG (2005). Peptides that fine-tune the serotonin system. Neuropeptides 39: 1-8.

Valentino RJ, Lucki I, Van Bockstaele E (2010). Corticotropinreleasing factor in the dorsal raphe nucleus: linking stress coping and addiction. Brain Res 1314: 29-37.

van Erp AM, Miczek KA (2000). Aggressive behavior, increased accumbal dopamine, and decreased cortical serotonin in rats. J Neurosci 20: 9320-9325.

Will MJ, Der-Avakian A, Bland ST, Grahn RE, Hammack SE, Sparks PD et al (2004). Electrolytic lesions and pharmacological inhibition of the dorsal raphe nucleus prevent stressor potentiation of morphine conditioned place preference in rats. Psychopharmacology (Berl) 171: 191-198.

Supplementary Information accompanies the paper on the Neuropsychopharmacology website (http://www.nature.com/npp) 